\title{
Abnormally High Thromboxane Biosynthesis in Homozygous Homocystinuria Evidence for Platelet Involvement and Probucol-sensitive Mechanism
}

\author{
Giovanni Di Minno, * Giovanni Davì, * * Maurizio Margaglione," Ferdinando Cirillo, * Elvira Grandone," Giovanni Ciabattoni," \\ Isabella Catalano, ' Pietro Strisciuglio, ${ }^{\ddagger}$ Generoso Andria, ${ }^{*}$ Carlo Patrono ${ }^{\ddagger \neq}$ and Mario Mancini * \\ Departments of ${ }^{*}$ Medicine and ${ }^{\ddagger}$ Pediatrics, University of Naples II School of Medicine, 80131 Naples; ${ }^{\S}$ Department of Molecular \\ Medicine, IRCCS Casa Sollievo della Sofferenza, 71013 S. Giovanni Rotondo; "Department of Pharmacology, Catholic University School \\ of Medicine, 00168 Rome; "Department of Medicine, University of Palermo School of Medicine, 90127 Palermo; Divisions of \\ ${ }^{* *}$ Hematology and ${ }^{\ddagger}$ Clinical Pharmacology, Department of Medicine, University of Chieti G. D'Annunzio School of Medicine, \\ 66013 Chieti, Italy
}

\begin{abstract}
Homocystinuria due to homozygous cystathionine $\beta$-synthase deficiency is an inborn error of metabolism characterized by a high incidence of thrombosis and premature atherosclerosis. We evaluated $T X A_{2}$ biosynthesis in vivo and several in vitro tests of platelet function in 11 homocystinuric patients and 12 healthy controls. In vitro, patients' platelet aggregation was within control values as were $\mathbf{T X B}_{2}$ formation, fibrinogen binding, and ATP secretion in response to thrombin. In contrast, the urinary excretion of 11-dehydro-TXB $\mathbf{T}_{2}$, a major enzymatic derivative of $\mathrm{TXA}_{2}$, was $>2 \mathrm{SD}$ of controls in all patients $(1,724 \pm 828 \mathrm{pg} / \mathrm{mg}$ creatinine, mean $\pm \mathrm{SD}$, in patients vs. $345 \pm 136$ in controls, $P<0.001)$. The administration to four patients of low-dose aspirin ( $50 \mathrm{mg} / \mathrm{d}$ for $1 \mathrm{wk}$ ) reduced metabolite excretion by $>80 \%$. The recovery of 11-dehydro- $\mathbf{T X B}_{2}$ excretion over the $10 \mathrm{~d}$ that followed aspirin cessation occurred with a pattern consistent with the entry into the circulation of platelets with intact cyclooxygenase activity. Prolonged partial reduction in the abnormally high excretion of both 11-dehydroTXB $_{2}$ and 2,3-dinor-TXB $\mathbf{T}_{2}$, was also observed in seven patients who ingested $500 \mathrm{mg}$ daily for 3 wk of the antioxidant drug probucol. These results provide evidence for enhanced thromboxane biosynthesis in homocystinuria and for its partial dependence on probucol-sensitive mechanisms. Furthermore, the elevated $\mathrm{TXA}_{2}$ formation in homocystinuria is likely to reflect, at least in part, in vivo platelet activation. ( $J$. Clin. Invest. 1993. 92:1400-1406.) Key words: cystathionine $\beta$-synthase deficiency $\bullet$ 11-dehydro-TXB $\mathrm{TX}_{2} \cdot 2,3$-dinor-TXB 2 - aspirin $\bullet$ antioxidant
\end{abstract}

Address correspondence and reprint requests to Dr. Patrono, Universita degli Studi “G. D'Annunzio," Palazzina Scuole di Specializzazione, Via dei Vestini 31, 66013, Chieti, Italy.

Received for publication 24 March 1992 and in revised form 22 April 1993

This paper has been presented in part at the XIII Congress of the International Society of Haemostasis and Thrombosis, at the VIII International Congress of Human Genetics, and at the 1992 Annual Meeting of the Association of American Physicians, and published in abstract form (Thromb. Haemostasis. 65:1102, 1991; Am. J. Hum. Genet. 49[Suppl]:166, 1991; Clin. Res. 40:202a[Abstr.] 1992).

Address correspondence and reprint requests to Dr. Patrono, Universita degli Studi “G. D'Annunzio," Palazzina Scuole di Specializzazione, Via dei Vestini 31, 66013 Chieti, Italy.

J. Clin. Invest.

(c) The American Society for Clinical Investigation, Inc. 0021-9738/93/09/1400/07 \$2.00

Volume 92, September 1993, 1400-1406

\section{Introduction}

Homocystinuria due to cystathionine $\beta$-synthase deficiency $(\mathrm{CBSD})^{1}$ is a recessively inherited error of metabolism strongly associated with premature atherosclerosis and arterial and venous thrombosis (1-4). Some hemostatic factors that may contribute to this tendency have been investigated in a large series of studies (5-13). Plasma coagulation factor VII, platelet survival, and antithrombin III activity have been reported to be abnormal (5-10). However, these claims have been challenged (11-13). Biochemical measurements of urinary TX metabolites and clinical trials with aspirin indicate that enhanced biosynthesis of $\mathrm{TXA}_{2}$ by platelets is an important contributor to the risk of thrombosis associated with several cardiovascular risk factors (14). Abnormally high levels of 2,3-dinor- $\mathrm{TXB}_{2}$, an enzymatic derivative of $\mathrm{TXA}_{2}$, have been reported in the urines of a CBSD patient (15). Therefore, we investigated $\mathrm{TXA}_{2}$ biosynthesis and its inhibition by low-dose aspirin, as reflected by the urinary excretion of its major metabolites, 11 dehydro-TXB ${ }_{2}$ and 2,3-dinor $T \mathrm{~TB}_{2}$, in a larger group of CBSD patients and controls with the aim of establishing the prevalence of this biochemical abnormality and its cellular source.

Hemostatic abnormalities involving antithrombin III, fibrinogen, plasminogen activator inhibitor-1, or tissue plasminogen activator have been reported in other clinical settings characterized by a thrombotic tendency (16-18). These abnormalities are currently thought to be associated with high circulating levels of thrombin. In addition to its role in the conversion of fibrinogen to fibrin, thrombin is a potent inducer of platelet $\mathrm{TXA}_{2}$ biosynthesis. Low levels of antithrombin III, the major plasma inhibitor of thrombin, have been reported in CBSD patients (6-8). To examine the possibility that the enhanced excretion of $\mathrm{TXA}_{2}$ metabolites in homocystinuria might be due to high circulating levels of thrombin, we measured several hemostatic variables that reflect a hypercoagulable state. The administration of probucol has been reported to prevent the increased $\mathrm{TXA}_{2}$ biosynthesis of cholesterol-fed rats (19). This has been suggested to depend on probucol-sensitive oxidative mechanisms (19). To gain insight into the mechanisms responsible for enhanced thromboxane biosynthesis in homocystinuria, the effects of a short-term course of probucol therapy on metabolite excretion were assessed in seven CBSD patients. Our results provide preliminary evidence that probucol may partially reduce the enhanced in vivo biosynthesis of $\mathrm{TXA}_{2}$ in homocystinuria.

1. Abbreviation used in this paper: CBSD, Homocystinuria due to cystathionine $\beta$-synthase deficiency. 


\section{Methods}

Subjects. 11 CBSD patients ( 5 females, 6 males, 8-39 yr) belonging to 8 unrelated families and 17 healthy control subjects ( 7 females, 10 males, 14-44 yr) were studied. None of the control subjects had a history of disease known to alter platelet function. All patients fulfilled the criteria (20) for the diagnosis of the homozygous form of CBSD in that all exhibited ectopia lentis, homocystinuria, and abnormally high plasma levels of methionine and homocystine with low or undetectable levels of cystine (21).

All but one (see Table $\mathrm{I}$ ) were responsive to pyridoxine and had been on pyridoxine treatment $(600-900 \mathrm{mg} / \mathrm{d})$ from the time of the diagnosis. The pyridoxine-unresponsive subject was on $8 \mathrm{~g} / \mathrm{d}$ betaine. Skin fibroblast cultures (22) showed an abnormally low activity $(<1 \%$ of controls) of cystathionine $\beta$-synthase in four patients. The other seven patients were not evaluated. For all the data reported in the results section, no statistically significant differences were found between the four patients tested and the other seven patients. All patients were comparable to controls with respect to renal function (patients vs. controls, mean $\pm 1 \mathrm{SD}$; serum creatinine concentration $0.77 \pm 0.2$ vs. $0.86 \pm 0.5 \mathrm{mg} / \mathrm{dl}$; urine creatinine concentration, $0.93 \pm 0.3$ vs. $1.0 \pm 0.5$ $\mathrm{mg} / \mathrm{dl}$; and blood urea nitrogen, $47.3 \pm 0.1$ vs. $30.2 \pm 0.3 \mathrm{mg} / \mathrm{dl}$ in controls); cigarette smoking; systolic ( $133 \pm 12$ vs. $147 \pm 9)$ and diastolic blood pressure ( $79 \pm 9$ vs. $84 \pm 10 \mathrm{mmHg}$; controls vs. patients, respectively); plasma glucose ( $83 \pm 17$ vs. $79 \pm 12 \mathrm{mg} / \mathrm{dl})$ and cholesterol $(150 \pm 14$ vs. $171 \pm 35 \mathrm{mg} / \mathrm{dl})$, and triglyceride levels ( $78 \pm 23$ vs. $97 \pm 48$ $\mathrm{mg} / \mathrm{dl}$ ) (patients vs. controls). No patient or control subject showed S-T depression or Q waves on ECG and all patients' clinical summaries were negative for angina pectoris or myocardial infarction. Also, all had normal peripheral pulses and were negative for bruits over the carotid vessels. Duplex scanner analysis confirmed the negativity with respect to carotid arteries, while it revealed early signs of atherosclerotic vascular disease of the iliac arteries in 4 of the 11 patients. The vascular studies of these patients have been reported in detail elsewhere (4). For all the data reported in the results section, no statistically significant differences were found between these four patients and the other seven homocystinuric subjects studied.

Materials. ADP and ATP sodium salts, Hepes, human albumin, hirudin, bovine fibrinogen, and trisodium citrate were from Sigma Chemical Co. (St. Louis, MO). ADP, ATP, and hirudin were dissolved in distilled water, prepared in $1 \mathrm{M}$ solutions and stored in small aliquots at $-20^{\circ} \mathrm{C}$. A $1 \mathrm{M}$ stock solution of Hepes was prepared in RPMI and stored at $4^{\circ} \mathrm{C}$. Trisodium citrate $(3.8 \%)$ was prepared in sterile, pyrogen-free water. Epinephrine (epinephrine hydrochloride, isotonic solution) was from Elkins-Sinn, Inc. (Cherry Hill, NJ). Thrombin was from Parke-Davis (Detroit, MI). It was dissolved in distilled water and stored in small aliquots at $-70^{\circ} \mathrm{C}$. Equine tendon collagen was from Hormon-Chemie (Munich, Germany) and arachidonate from $\mathrm{Nu}$ Check Prep, Inc. (Elysian, MN). Firefly luciferase and luciferin (Chronolume 395) was from Chrono-Log Corp. (Havertown, PA). Silicone oils (methyl silicone 1.0 DC 200 and hi-phenyl silicone 125 DC 550) were purchased from W. F. Nye, Specialty Lubricants (New Bedford, MA). Mixtures of DC 200 and DC 550 and solutions of Chronolume as well as of the sodium salt of arachidonic acid were prepared as previously described (23). Sep-Pak C18 cartridges were from Waters Associates (Milford, MA); 11-dehydro- ${ }^{3} \mathrm{H}-\mathrm{TXB}_{2}$ ( 70 $120 \mathrm{Ci} / \mathrm{mmol}$ ) was purchased from Amersham Amity (Milan, Italy); and authentic $\mathrm{TXB}_{2}, 2,3$-dinor $\mathrm{TXB}_{2}$, and 11-dehydro- $\mathrm{TXB}_{2}$ were kindly provided by Dr. J. Pike (The Upjohn Co., Kalamazoo, MI). Iodogen (1,3,4,6-tetrachloro-3-6-diphenylglycouril) was from Pierce Eurochemie (Oud Beijerland, The Netherlands). Human melanoma tissue plasminogen activator was obtained from Dr. D. Collen, Centre for Thrombosis and Vascular Research (Leuven, Belgium). Human plasminogen, $\mathrm{CnBr}$-digested human fibrinogen, plasminogen activator inhibitor-1-depleted plasma and the chromogenic substrate for the assay of the activity of plasminogen activator inhibitor-1 were from Ortho Diagnostics (Milan, Italy). The kit for the measurement of the coagulant activity of fibrinogen (Clauss method) was from General
Diagnostics (Milan, Italy) whereas that for the functional determination of antithrombin III was from Boehringer-Biochemia-Robin (Milan, Italy).

Urinary 11-dehydro- $T X B_{2}$ and 2,3-dinor-TXB ${ }_{2}$ assays. These measurements were carried out on 20-ml aliquots of urine adjusted to $\mathrm{pH}$ 4.0-4.5 with formic acid, run on Sep-Pak C18 cartridges, and eluted with ethyl acetate. The eluate was then chromatographed on silicic acid columns, eluted with benzene/ethyl acetate/methanol (60:40:30), and immunoreactive 11-dehydro- $\mathrm{TXB}_{2}$ was measured by a previously described RIA $(24,25)$. This assay has been validated for the measurement of metabolite levels in human urine by comparison with negative ion-chemical ionization gas-chromatography/mass spectrometry (24). Immunoreactive 2,3-dinor- $\mathrm{TXB}_{2}$ was measured by a previously validated RIA (26) after separating the metabolite from $\mathrm{TXB}_{2}$. This was achieved by subjecting the eluates prepared for 11-dehydro- $\mathrm{TXB}_{2}$ measurements to reverse-phase high pressure liquid chromatography (solvent system, acetonitrile/water/acetic acid [27:73:0.18]; flowrate, $0.5 \mathrm{ml} / \mathrm{min}$ ). Urine creatinine was determined according to the manufacturer's recommendations (Behring Testomar-Creatinina Combipack, Scoppito, Italy).

Studies on platelets and fibrinolysis. Aggregation of platelets in platelet-rich plasma, $\mathrm{TXB}_{2}$ synthesis, and ATP secretion in response to 1 or $5 \mathrm{U} / \mathrm{ml}$ thrombin, preparation of suspensions of washed platelets, purification and labeling of human fibrinogen, thrombin-dependent fibrinogen binding, and analysis of the binding data were performed as previously described (23). For studies on the sensitivity of platelets to aggregating agents, the $\mathrm{AC}_{50}$ was calculated. This was defined as the concentration of an agonist that produced $50 \%$ light transmittance within $3 \mathrm{~min}$ after addition to the platelet suspension. For binding studies, hirudin was added in microliter volumes at a final concentration of $0.1 \mathrm{U} / \mathrm{ml}$ to unstirred platelet suspensions to prevent clotting of fibrinogen by thrombin $(0.1 \mathrm{U} / \mathrm{ml})$. Fibrinolytic activity in the plasma euglobulin fraction was determined before and after $10 \mathrm{~min}$ of venous stasis and expressed in tissue plasminogen activator equivalent units with reference to data obtained using purified melanoma tissue plasminogen activator. Tissue plasminogen activator- and inhibitor-1-related antigens were measured by an ELISA method according to the manufacturer's recommendations, whereas the biological activity of the plasminogen activator inhibitor was studied by an amidolytic assay (27).

Other assays. The total cholesterol, triglyceride, and plasma glucose levels were measured according to standard procedures (27).

Clinical protocols. Informed consent was obtained from all patients and volunteers after approval of the protocols by the Human Investigation Committee, and the studies were carried out according to the principles expressed in the Declaration of Helsinki. Because aspirin is present in so many over-the-counter preparations, all subjects were asked to avoid cold remedies during the study. Neither patients nor controls had taken any medication known to interfere with arachidonate metabolism or platelet function for $\geq 1 \mathrm{wk}$ before blood sampling. On every occasion and for each subject, after 12-15 h of overnight fasting, $45 \mathrm{ml}$ of blood was collected at 9-9.30 a.m., from the antecubital vein, via a 19-gauge scalp vein needle, into a sterile plastic tube containing $5 \mathrm{ml}$ of sterile $3.8 \%$ trisodium citrate, and was immediately processed.

In the first phase of the study, a comparison of 11-dehydro- $\mathrm{TXB}_{2}$ excretion and in vitro platelet function between CBSD patients and controls was performed. For these determinations, blood samples collected in the morning as reported above, and the urines, collected during the overnight fasting, were used. The urines were immediately frozen and kept at $-70^{\circ} \mathrm{C}$ until extracted. Nine CBSD patients were studied after being on long-term treatment with pyridoxine (Table I). Two newly diagnosed patients were studied both before and 4-12 wk after starting pyridoxine. To further investigate the potential effect of this therapy on 11-dehydro- $\mathrm{TXB}_{2}$ excretion, three healthy volunteers (all males, aged 26-30 yr) were instructed to take pyridoxine $900 \mathrm{mg} / \mathrm{d}$ for $4 \mathrm{wk}$ and urines were collected twice before treatment and at 1, 2, 3, and $4 \mathrm{wk}$ on treatment. Results from the first phase of the study indicated an abnormally high 11-dehydro- $\mathrm{TXB}_{2}$ excretion and a normal in 
Table I. Clinical Features of the CBSD Patients

\begin{tabular}{|c|c|c|c|c|c|}
\hline Patient & Sex & $\begin{array}{l}\text { Duration of } \\
\text { treatment* }\end{array}$ & $\begin{array}{l}\text { Age at } \\
\text { diagnosis }\end{array}$ & $\underset{\text { responsive }}{\text { B }_{6}}$ & $\begin{array}{c}\text { Cystathionine } \\
\beta \text {-synthase } \\
\text { activity }\end{array}$ \\
\hline \multicolumn{5}{|c|}{$y r$} & $\%$ \\
\hline SR & $\mathrm{F}$ & 12 & 6 & + & ND \\
\hline SS & F & 12 & 2 & + & ND \\
\hline DAM & $F$ & 12 & 10 & + & ND \\
\hline DA & $\mathbf{M}$ & 12 & 12 & + & ND \\
\hline MA & $\mathrm{F}$ & 13 & 9 & + & $<1$ \\
\hline ML & $\mathbf{M}$ & 13 & 3 & + & $<1$ \\
\hline $\mathrm{QE}$ & $\mathbf{M}$ & 14 & 25 & + & $<1$ \\
\hline IA & $\mathbf{M}$ & 13 & 13 & + & $<1$ \\
\hline $\mathrm{TG}^{\ddagger}$ & $\mathbf{M}$ & 10 & 4 & - & ND \\
\hline PV & $\mathbf{M}$ & - & 28 & + & ND \\
\hline TL & $F$ & - & 8 & + & ND \\
\hline
\end{tabular}

* Pyridoxine, $600-900 \mathrm{mg} / \mathrm{d}$. ${ }^{\ddagger} \mathrm{B}_{6}$ nonresponsive, on treatment with betaine $(8 \mathrm{~g} / \mathrm{d})$. ND, not determined.

vitro platelet function in CBSD. Therefore, we examined the relative contribution of platelets to the enhanced metabolite excretion and the hypothesis that a hypercoagulable state might be involved in this in vivo abnormality of arachidonate metabolism. To address the first issue, four CBSD patients were instructed to ingest $50 \mathrm{mg}$ aspirin (Bayer Italia, Milan, Italy) daily for $1 \mathrm{wk}$ with the evening meal. 12-hr urines were collected before, on the 4th and 7th day during treatment, and on the 4th and 10th day after stopping aspirin. To address the second issue, peripheral venous blood was obtained from nine patients on two different occasions before the aspirin study, and plasma samples were immediately processed for the measurement of a series of hemostatic variables.

In the last phase of the study, 500-mg tablets of probucol (Lurselle; Lepetit, Milan, Italy) were administered daily for 3 wk to 7 patients, and 12-h urines were collected before, on the last day of treatment, and 3 wk later. To determine whether the inhibitory effect of probucol on 11-dehydro- $\mathrm{TXB}_{2}$ excretion was due to impaired $\mathrm{TXA}_{2}$ biosynthesis or to a shift in its metabolic disposition from the 11-hydroxydehydrogenase pathway (28), the urinary excretion of the metabolite generated through the $\beta$-oxidation pathway, 2,3-dinor- $\mathrm{TXB}_{2}$, was also measured. To interpret changes in 11-dehydro- $\mathrm{TXB}_{2}$ excretion associated with probucol administration to CBSD patients, 5 healthy subjects were instructed to take $500 \mathrm{mg}$ probucol daily for $3 \mathrm{wk}$, and 12-h urines were collected before; at the end of the 1st, 2nd, and 3rd wk of treatment; and during the following $3 \mathrm{wk}$ of wash out.

Statistical analysis. Results are expressed as means \pm 1 SD. The distribution of the variables was analyzed by nonparametric comparisons, the variance by the Kruskall-Wallis method, and pairwise comparisons by the Mann-Whitney $U$ test.

\section{Results}

Studies on the urinary excretion of 11-dehydro-TXB $B_{2}$. In control subjects the urinary excretion of 11-dehydro-TXB ${ }_{2}$ averaged $345 \pm 136 \mathrm{pg} / \mathrm{mg}$ creatinine (range, 138-606). CBSD patients had significantly $(P<0.001)$ higher metabolite excretion: $1,724 \pm 828 \mathrm{pg} / \mathrm{mg}$ creatinine. All patients had metabolite excretion $>2$ SD above the control mean. Enhanced thromboxane biosynthesis was unrelated to cardiovascular risk factors and independent of detectable atherosclerotic vascular disease (Table II). 11-dehydro-TXB ${ }_{2}$ measurements were highly
Table II. Urinary Excretion of 11-Dehydro-TXB in CBSD Patients, in Relation to Blood Lipids and Glucose and Presence of Vascular Disease

\begin{tabular}{|c|c|c|c|c|c|}
\hline \multirow[b]{2}{*}{ Patient } & \multicolumn{3}{|c|}{ Plasma } & \multirow{2}{*}{$\begin{array}{l}\text { Atherosclerotic } \\
\text { vascular } \\
\text { disease* }\end{array}$} & \multirow{2}{*}{$\begin{array}{c}\text { 11-dehydro-TXB } \\
\text { excretion }\end{array}$} \\
\hline & Cholesterol & TG & Glucose & & \\
\hline & & ng/dl & & & $\begin{array}{c}p g / m g \\
\text { creatinine }\end{array}$ \\
\hline SR & 152 & 85 & 96 & - & 2,173 \\
\hline SS & 170 & 63 & 75 & + & 3,280 \\
\hline DAM & 141 & 100 & 103 & + & 1,312 \\
\hline DA & 149 & 99 & 80 & - & 1,562 \\
\hline MA & 157 & 86 & 109 & + & 1,234 \\
\hline ML & 143 & 60 & 92 & - & 1,530 \\
\hline $\mathrm{QE}$ & 166 & 73 & 77 & - & 921 \\
\hline IA & 140 & 62 & 86 & - & 2,062 \\
\hline TG & 169 & 54 & 73 & + & 1,250 \\
\hline PV & 134 & 124 & 69 & - & 649 \\
\hline TL & 132 & 51 & 50 & - & 2,996 \\
\hline
\end{tabular}

* Assessed by duplex scanner analysis and defined as $>15 \%$ narrowing of iliac arteries (4). ${ }^{\ddagger}$ In 12 healthy subjects, 11-dehydro- $\mathrm{TXB}_{2}$ averaged $345 \pm 136 \mathrm{pg} / \mathrm{mg}$ creatinine (range: $138-606$ ). TG, triglycerides.

reproducible upon repeated sampling. Over a 1-yr period, three different collections from three CBSD patients showed that the intrasubject coefficient of variation did not exceed $16 \%(3,280$, 3,201 , and $3,351 \mathrm{pg} / \mathrm{mg}$ creatinine in the urines from S.S.; 2,173, 2,791, and 2,269 in those from S.R.; and 1,250, 1,308, and 956, in those from T.G.). Two newly diagnosed patients (P.V. and T.L., see Table I) provided an opportunity to assess the potential impact of pyridoxine treatment on urinary 11-dehydro-TXB $\mathrm{T}_{2}$ excretion. Patient P.V. had a baseline excretion rate of $649 \mathrm{pg} / \mathrm{mg}$ creatinine and repeated measurements at 4 and 12 wk after starting therapy yielded comparable values of 696 and 547, respectively (intrasubject CV, 12\%). Patient T.L. had two baseline measurements of 11 -dehydro-TXB of $_{2}, 891$ and $3,101 \mathrm{pg} / \mathrm{mg}$ creatinine and a third one while on pyridoxine treatment since 6 wk of 2,703 (intrasubject CV, 7\%). To further document that this form of treatment is not responsible for the changes observed, 11-dehydro- $\mathrm{TXB}_{2}$ excretion was measured in three healthy subjects before and up to 4 wk after starting pyridoxine treatment. Metabolite excretion averaged $385 \pm 151$ and $365 \pm 126 \mathrm{pg} / \mathrm{mg}$ creatinine on two separate occasions before treatment and remained relatively stable at $313 \pm 133,350 \pm 138,381 \pm 96$, and $369 \pm 145$ at $1,2,3$, and 4 wk of pyridoxine $900 \mathrm{mg} / \mathrm{d}$ (intrasubject CV, 10.2 $\pm 6.3 \%$ ).

Effect of low-dose aspirin. To characterize the cellular origin of the enhanced biosynthesis of TXA $\mathrm{TH}_{2}$ in CBSD, we evaluated the short-term effects of a relatively platelet-selective regimen of aspirin $(50 \mathrm{mg} / \mathrm{d}$ for $1 \mathrm{wk}$ ) in four patients (S.R., S.S., Q.E., and T.G.). Before the administration of aspirin, the rate of urinary 11-dehydro- $\mathrm{TXB}_{2}$ excretion averaged 1,977 \pm 1068 $\mathrm{pg} / \mathrm{mg}$ creatinine. After 4 and $7 \mathrm{~d}$ of treatment, metabolite excretion was reduced by $82-84 \%$ ( $348 \pm 287$ and $309 \pm 293 \mathrm{pg}$ / $\mathrm{mg}$, respectively, $P<0.001$ vs. preaspirin values). After withdrawal of aspirin, the pattern of 11-dehydro- $\mathrm{TXB}_{2}$ excretion (Fig. 1) was consistent with a platelet origin of the parent compound, its recovery being compatible with the slow entry into 


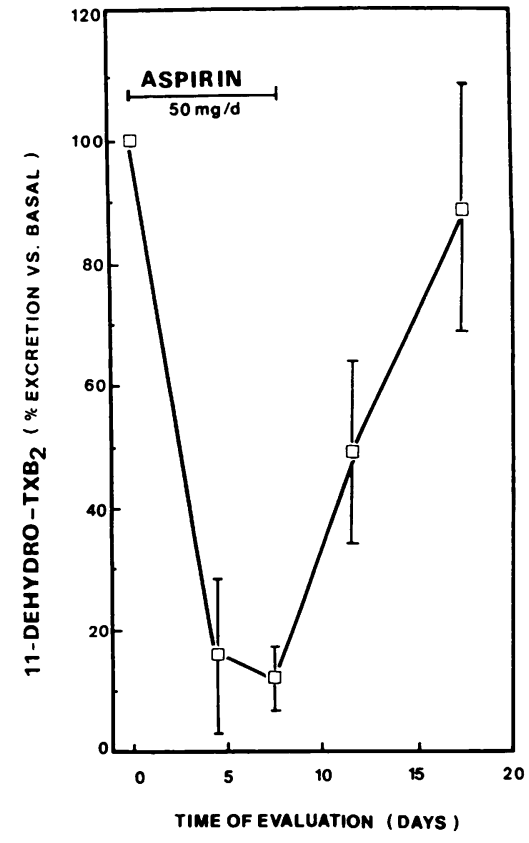

Figure 1. Urinary excretion of 11-dehydro$\mathrm{TXB}_{2}$ during and after 1-wk administration of low-dose aspirin ( 50 $\mathrm{mg} / \mathrm{d}$ ) to four CBSD patients. The excretion of the metabolite is expressed as percentage (mean \pm SD) of preaspirin levels. Each patient served as her/his own control.

the circulation of platelets with intact cyclooxygenase activity (29-33).

Studies on platelets, coagulation, and fibrinolysis. As shown in Table III, aggregation of platelets, as well as thrombin-dependent $\mathrm{TXB}_{2}$ synthesis, ATP secretion, and fibrinogen

Table III. Platelet, Coagulation, and Fibrinolytic Parameters in CBSD Patients and Controls

\begin{tabular}{|c|c|c|}
\hline Parameter & $\begin{array}{l}\text { Control } \\
\text { subjects }\end{array}$ & $\begin{array}{c}\text { CBSD } \\
\text { patients }\end{array}$ \\
\hline \multicolumn{3}{|l|}{ Platelet aggregation $\left(\mathrm{AC}_{50}\right)$} \\
\hline $\mathrm{ADP}(\mu \mathrm{g} / \mathrm{M})$ & $1.8 \pm 0.6$ & $1.3 \pm 0.3$ \\
\hline Collagen $(\mu \mathrm{g} / \mathrm{ml})$ & $0.6 \pm 0.2$ & $0.4 \pm 0.2$ \\
\hline Arachidonate (mM) & $0.5 \pm 0.2$ & $0.4 \pm 0.3$ \\
\hline Epinephrine $(\mu \mathrm{M})$ & $5.1 \pm 0.3$ & $4.6 \pm 1.5$ \\
\hline \multicolumn{3}{|l|}{ Platelet ATP secretion } \\
\hline$\left(\mu \mathrm{mol} / 10^{11} \mathrm{plts}\right)$ & $3.2 \pm 0.4$ & $3.6 \pm 0.3$ \\
\hline \multicolumn{3}{|l|}{ Platelet $\mathrm{TXB}_{2}$} \\
\hline \multicolumn{3}{|l|}{ Platelet fibrinogen binding } \\
\hline molecules/plt $\left(\times 10^{4}\right)$ & $6.0 \pm 0.8$ & $6.3 \pm 0.6$ \\
\hline$K_{\mathrm{d}}(\mu \mathrm{M} /$ liter $)$ & $0.2 \pm 0.07$ & $0.3 \pm 0.0$ \\
\hline Plasma fibrinogen (mg/liter) & $25.4 \pm 2.8$ & $28.0 \pm 3.6$ \\
\hline Antithrombin III (U/ml) & $9.7 \pm 1.8$ & $10.4 \pm 0.7$ \\
\hline \multicolumn{3}{|l|}{$\mathrm{t}-\mathrm{PA}$ antigen $(\mathrm{ng} / \mathrm{ml})$} \\
\hline Prestasis & $4.5 \pm 2.4$ & $5.5 \pm 1.7$ \\
\hline Poststasis & $14.4 \pm 6.3$ & $12.0 \pm 6.2$ \\
\hline \multicolumn{3}{|l|}{ Fibrinolytic activity (U/ml) } \\
\hline Prestasis & $1.5 \pm 0.3$ & $1.6 \pm 0.9$ \\
\hline Poststasis & $10.8 \pm 4.9$ & $7.4 \pm 3.8$ \\
\hline PAI-1 antigen $(\mathrm{ng} / \mathrm{ml})$ & $13.9 \pm 4.3$ & $17.6 \pm 4.7$ \\
\hline PAI activity $(\mathrm{U} / \mathrm{ml})$ & $8.0 \pm 2.6$ & $9.8 \pm 2.5$ \\
\hline
\end{tabular}

Each value is the mean \pm 1 SD of the data obtained in 9 CBSD patients and 10 healthy control subjects. $P>0.05$ for all comparisons between patients and controls. plt, platelet; t-PA: tissue plasminogen activator; PAI: plasminogen activator inhibitor. binding were comparable in CBSD patients and controls. Likewise, the coagulation and fibrinolytic factors analyzed were all within control values. These values are similar to those previously reported for normal subjects (16-18). No correlation was found between any of the parameters reported in this section and 11-dehydro-TXB ${ }_{2}$ excretion in CBSD.

Effect of probucol on 11-dehydro- $T X B_{2}$ and 2,3-dinor-TX $B_{2}$ excretion. To gain insight into the mechanism(s) responsible for enhanced $\mathrm{TXA}_{2}$ biosynthesis in CBSD, the antioxidant drug probucol was given daily for $21 \mathrm{~d}$ to seven patients (S.R., S.S., D.A.M., D.A., M.A., M.L., and T.G.). The rate of TX metabolite excretion at baseline averaged $1,647 \pm 981 \mathrm{pg} / \mathrm{mg}$ creatinine. At the end of probucol treatment (Fig. 2, top), 11dehydro- $\mathrm{TXB}_{2}$ excretion was reduced by $\sim 40 \%(P<0.01$ vs. preprobucol values). Plasma cholesterol was also significantly $(P<0.05)$ reduced from $154 \pm 12$ to $131 \pm 9 \mathrm{mg} / \mathrm{dl} .3 \mathrm{wk}$ after withdrawing drug therapy, at a time when plasma cholesterol was comparable to baseline values $(140 \pm 35, P>0.05), 11$-dehydro-TXB ${ }_{2}$ excretion was still significantly reduced $(P$ $<0.005$ vs. preprobucol data). We interpret this prolonged inhibition to reflect the very long half-life of the drug (34). The response to probucol showed a large interindividual variation in that the patients experienced a $30-70 \%$ reduction in metabolite excretion. The effect of probucol on $\mathrm{TXA}_{2}$ biosynthesis was further analyzed by measuring the urinary excretion of the metabolite generated through the $\beta$-oxidation pathway, 2,3-dinor$\mathrm{TXB}_{2}$ (28). At baseline, CBSD patients had significantly ( $P$ $<0.005$ ) higher 2,3-dinor- $\mathrm{TXB}_{2}$ excretion than control subjects $(697 \pm 538 \mathrm{pg} / \mathrm{mg}$ creatinine in CBSD, range: $351-1,888$, vs. $214 \pm 111 \mathrm{pg} / \mathrm{mg}$ creatinine in controls, range: $63-345)$. Six of the seven patients had urinary metabolite excretion $>2$ SD above the control mean. $3 \mathrm{wk}$ after withdrawing probucol treat-

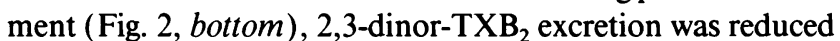
to $355 \pm 231$ ( $P<0.005$ vs. preprobucol data). As for 11-dehydro- $\mathrm{TXB}_{2}$, the effect of probucol on 2,3-dinor- $\mathrm{TXB}_{2}$ excretion showed a large interindividual variability in that the patients exhibited a $30-80 \%$ reduction in metabolite excretion. When the individual data from samples obtained $3 \mathrm{wk}$ after withdrawing probucol therapy were analyzed, a statistically signifcant correlation $(r=0.76, P<0.05)$ was found between the

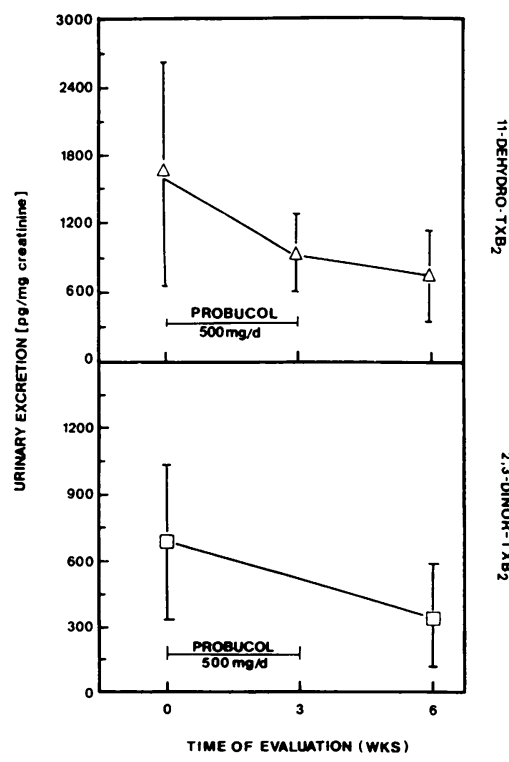

Figure 2. Urinary excretion of 11-dehydro$\mathrm{TXB}_{2}$ (top) and 2,3dinor- $\mathrm{TXB}_{2}$ (bottom) during and after 3-wk administration of probucol $(500 \mathrm{mg} / \mathrm{d})$ to seven CBSD patients. Mean \pm 1 SD values are represented. For both metabolites, $P<0.005$ time 0 vs. 6 -wk values. For 11-dehydro-TXB , $_{2}$ $P<0.01$ time 0 vs. 3 -wk or 3-vs. 6-wk values. 


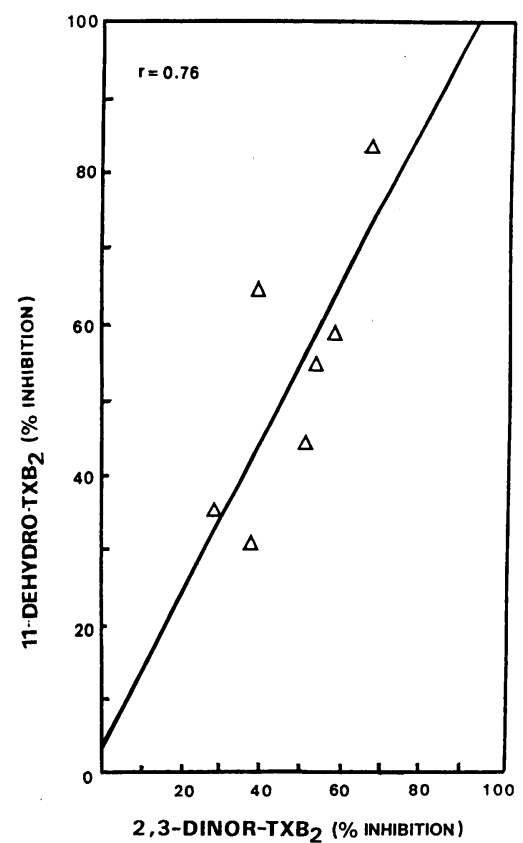

Figure 3. Correlation between percentage reduction in the excretion of 11-dehydro-TXB ${ }_{2}$ and that of 2,3-dinor$\mathrm{TXB}_{2}$ after probucol administration ( 500 $\mathrm{mg} / \mathrm{d}$ for $3 \mathrm{wk}$ ). Individual data from seven CBSD patients 3 wk after withdrawing drug therapy are depicted. Linear-regression analysis yielded a statistically significant correlation $(r$ $=0.76, P<0.05$ ) between percentage reductions of the two metabolites.

reduction in urinary excretion of 11-dehydro- $\mathrm{TXB}_{2}$ and that of 2,3-dinor-TXB 2 (Fig. 3).

At variance with the effect on $\mathrm{TXB}_{2}$ metabolite excretion observed in CBSD, the same regimen of probucol did not affect 11-dehydro- $\mathrm{TXB}_{2}$ excretion in five control subjects to any statistically significant extent. Thus, metabolite excretion averaged $360 \pm 115 \mathrm{pg} / \mathrm{mg}$ creatinine at baseline; 368 \pm 86 , $320 \pm 116$, and $392 \pm 124$ at the end of the 1st, 2 nd, and $3 \mathrm{rd} \mathrm{wk}$ of probucol administration; respectively, and remained stable at $388 \pm 108,373 \pm 94$, and $401 \pm 115 \mathrm{pg} / \mathrm{mg}$ creatinine over the following 3 wk after drug withdrawal.

\section{Discussion}

In its homozygous form, homocystinuria due to cystathionine $\beta$-synthase deficiency is characterized by multiple biochemical abnormalities, mental retardation, ectopia lentis, osteoporosis, premature atherosclerosis, and venous and arterial thrombosis. Although the mechanism is largely unknown, the administration of pharmacological doses of vitamin $B_{6}(100-1,000 \mathrm{mg} / \mathrm{d})$ appears to correct, at least in part, most clinical symptoms and biochemical abnormalities in about half of the patients. In contrast, the problem of premature atherosclerosis and its thrombotic complications continues to be an important one in the management of CBSD (1-4). At variance with the homozygous state, heterozygosity for homocystinuria is a rather common entity ( 1 of 100-200 live births) and recent reports $(3,4$, 35 ) indicate that the homocystinuric trait is associated with a similar tendency to atherosclerosis and its thrombotic complications. The pathophysiological and clinical implications of this disease, as well as the observation that abnormalities in platelet arachidonate metabolism are often present in patients at risk for thrombosis (14), prompted us to study thromboxane biosynthesis in CBSD. The urinary excretion of 11-dehydro$\mathrm{TXB}_{2}$, a major enzymatic derivative of $\mathrm{TXA}_{2}$, was approximately fivefold higher in CBSD patients than controls. This alteration was independent of the presence of other cardiovascular risk factors or atherosclerotic vascular disease. Moreover, the finding of similarly increased excretion of 2,3-dinor-TXB strongly argues for these biochemical changes reflecting enhanced biosynthesis of $\mathrm{TXA}_{2}$ rather than altered metabolic disposition in the setting of CBSD.

Urinary eicosanoid metabolites do not reflect a specific site of eicosanoid biosynthesis (14). In an attempt to characterize the cellular source of the abnormally high $\mathrm{TXA}_{2}$ biosynthesis in homocystinuria, we administered aspirin, $50 \mathrm{mg}$ daily for 1 wk, and evaluated the pattern of inhibition and recovery of 11-dehydro- $\mathrm{TXB}_{2}$ excretion in four patients. This regimen is known to impair platelet $\mathrm{TXA}_{2}$ synthesis in a relatively selective cumulative fashion $(30,31)$. The finding of $82-84 \%$ suppression of TX metabolite excretion upon repeated daily dosing with $50 \mathrm{mg}$ of aspirin suggests that this was achieved through a process of cumulative inhibition, inasmuch as a single administration of the same dose only produces $50 \%$ inhibition of platelet cyclooxygenase activity (30). A pattern of cumulative inhibition is consistent with the rate of enzyme turn over or cell renewal being longer than the 24-h dosing interval. Both such profound suppression and the incomplete recovery of TX metabolite excretion at 4 and $7 \mathrm{~d}$ after aspirin withdrawal are compatible with this pattern, reflecting cumulative acetylation by aspirin of platelet prostoglandin/H-synthase and the slow entry of new platelets with intact enzyme into the systemic circulation, respectively. However, these considerations do not exclude the possibility that extraplatelet sources (e.g., macrophages infiltrating atherosclerotic lesions) of $\mathrm{TXA}_{2}$ biosynthesis may contribute, at least in part, to enhanced metabolite excretion in the setting of homozygous homocystinuria.

In type II diabetes mellitus, enhanced TX biosynthesis is associated with increased in vitro sensitivity of platelets to aggregating agents (36). Therefore, we examined platelet function ex vivo. The data obtained indicate that platelets from CBSD patients aggregate, secrete ATP, form $\mathrm{TXB}_{2}$, and bind fibrinogen in a fashion indistinguishable from controls. Changes in the plasma levels of some hemostatic variables are thought to be associated with high circulating levels of thrombin (15-18). To address the possibility that thrombin might be involved in the abnormally high $\mathrm{TXA}_{2}$ biosynthesis in homocystinuria, we measured several hemostatic indexes of hypercoagulability. The results obtained argue against the hypothesis of an hypercoagulable state being responsible for platelet activation resulting in enhanced $\mathrm{TXA}_{2}$ biosynthesis.

Kaplan et al. (19) have shown that the antioxidant drug probucol prevented the hemodynamic abnormalities as well as the increased $\mathrm{TXA}_{2}$ biosynthesis in rats on short-term cholesterol feeding. To gain insight into the mechanism(s) responsible for enhanced $\mathrm{TXA}_{2}$ biosynthesis in homocystinuria, we evaluated the effects of a 3-wk administration of probucol on the urinary excretion of 11-dehydro- $\mathrm{TXB}_{2}$ and 2,3-dinor$\mathrm{TXB}_{2}$. Both were partially, though persistently, reduced by this treatment, suggesting an effect of probucol on TXA $\mathrm{TX}_{2}$ biosynthesis. This is unlikely to reflect a direct inhibitory effect of probucol on platelet function or enzymes involved in arachidonate metabolism, inasmuch as 11-dehydro- $\mathrm{TXB}_{2}$ excretion was unaltered in control subjects exposed to the same drug regimen. The study of Kaplan et al. (19) showed that although the administration of probucol did not affect the feeding-related rise in low density lipoproteins, and only partially prevented that of total cholesterol, it entirely corrected the increased $\mathrm{TXB}_{2}$ excretion of cholesterol-fed rats. Cholesterol levels were entirely normal in our patients, and no correlation was found between 
baseline levels of plasma cholesterol and urinary 11-dehydro$\mathrm{TXB}_{2}$ (Table II). $3 \mathrm{wk}$ after withdrawing probucol, the urinary excretion of TX metabolites was still significantly reduced, at a time when plasma cholesterol was not significantly different from preprobucol values.

Thus, although elevated levels of plasma cholesterol may be causally related to elevated 11-dehydro- $\mathrm{TXB}_{2}$ excretion in type IIa hypercholesterolemia (37), the rather trivial (9-15\%) reduction in blood cholesterol vis-a-vis the $40-60 \%$ drop in TX metabolite excretion, the lack of correlation between the two, and the time-dependent dissociation of the observed changes during and after probucol treatment, all argue against the involvement of cholesterol in the enhanced TXA $\mathrm{TH}_{2}$ biosynthesis in homocystinuria as well as in its partial correction by probucol. The production of oxidized low density lipoproteins is facilitated by thiol compounds, including homocysteine $(38,39)$. Oxidized low density lipoproteins induce platelet activation and TX formation (40). In vitro incubation of platelet-rich plasma with homocysteine increases the formation of $\mathrm{TXB}_{2}$ by platelets (41). In vitro, probucol prevents the oxidative modification of low density lipoproteins $(34,42)$. Thus, in spite of the limitations inherent to a short-term, open study, inhibition by probucol of the elevated $\mathrm{TXA}_{2}$ biosynthesis is consistent with the possibility that in vivo oxidized low density lipoproteins mediate, at least in part, the increased platelet arachidonate metabolism in homocystinuria.

It has also been suggested that probucol's antiatherosclerotic activity may be related to inhibition of interleukin 1 secretion by macrophages $(43,44)$. Thus, an effect of probucol on extraplatelet sources of TXA $\mathrm{TX}_{2}$ biosynthesis, independent of its antioxidant activity, cannot be excluded by our findings. The possibility of an important role of macrophages would be consistent with unaltered platelet $\mathrm{TXA}_{2}$ production in vitro and enhanced $\mathrm{TXA}_{2}$ biosynthesis in vivo, as detected in our CBSD patients. The use of MDL 29,311, which is an analogue of probucol that does not lower cholesterol but does have full antioxidant activity (45), or other antioxidant interventions might help to clarify these mechanistic uncertainties.

These results provide biochemical evidence of enhanced TXA $_{2}$ biosynthesis in homocystinuria and of its partial dependence on probucol-sensitive mechanisms. Our data also suggest that this abnormality may reflect the activation of platelets and other cells with comparable aspirin sensitivity in response to stimuli operating in vivo, the nature of which remains to be determined. We believe that information from these studies allows for a better understanding of the tendency to thrombosis in homocystinuria and helps identify the mechanism( $\mathrm{s}$ ) of homocysteinemia as a risk factor for atherosclerotic cardiovascular disease. Finally, our results provide a rationale for testing the efficacy and safety of low-dose aspirin in this setting.

\section{Acknowledgments}

The authors thank Drs. M. Colucci, N. Semeraro, M. J. Silver, E. Tremoli, and F. Violi for valuable suggestions. The expert editorial assistance of Ms. Marina Ruzzi is gratefully acknowledged.

These studies were supported by grants from the Italian National Research Council (CNR), Progetto Strategico Malattie Orfane, Sottoprogetto Omocistinuria, and Progetto Finalizzato Prevenzione e Controllo dei Fattori di Malattia SP8 (91.00216.PF41 and 92.00152.PF41).

\section{References}

1. Mudd, S. H., F. Skovby, H. L. Levy, K. D. Pettigrew, B. Wilcken, R. E. Pyeritz, G. Andria, G. H. J. Boers, I. L. Bromberg, R. Cerone, et al. 1985. The natural history of homocystinuria due to cystathionine $\beta$-synthase deficiency. Am. J. Hum. Genet. 37:1-31.

2. Brattstrom, L., J. E. Hardebo, and B. Hultberg. 1984. Moderate homocysteinemia. A possible risk factor for arteriosclerotic cerebrovascular disease. Stroke. 15:1012-1016.

3. Boers, G. H. J., A. G. H. Smals, F. J. M. Trijbels, B. Fowler, J. A. J. M. Bakkeren, H. C. Schoonderwaldt, W. J. Kleijer, and P. W. C. Kloppenborg. 1985. Heterozygosity for homocystinuria in premature peripheral and cerebral occlusive arterial disease. N. Engl. J. Med. 313:709-715.

4. Rubba, P., F. Faccenda, P. Pauciullo, L. Carbone, M. Mancini, P. Strisciuglio, R. Carrozzo, R. Sartorio, E. del Giudice, and G. Andria. 1990. Early signs of vascular disease in homocystinuria: a noninvasive study by ultrasound methods in eight families with cystathionine- $\beta$-synthase deficiency. Metab. Clin. Exp. 39:1191-1195.

5. Harker, L. A., S. J. Slichter, C. R. Scott, and R. Ross. 1974. Homocystinemia. Vascular injury and arterial thrombosis. N. Engl. J. Med. 291:537-543.

6. Giannini, M. J., M. Coleman, and I. Innerfield. 1974. Antithrombin activity in homocystinuria. Lancet. i: 1094.

7. Maruyama, I., R. Fukuda, M. Kaszama, T. Abe, Y. Yoshida, and A. Igata. 1977. A case of homocystinuria with low antithrombin activity. Acta Haematol. Jpn. 40:267-271.

8. Palareti, G., S. Salardi, S. Piazzi, C. Legnani, M. Poggi, F. Grauso, A. Caniato, S. Coccheri, and E. Cacciari. 1986. Blood coagulation changes in homocystinuria: effects of pyridoxine and other specific therapy. J. Pediatr. 109:10011006.

9. Merckz, J., and F. Kuntz. 1981. Deficit en facteur VII et homocystinurie: association fortuite ou syndrome? Nouv. Presse Med. 10:3796.

10. Munnich, A., J. M. Saudbray, M. D. Dautzenberg, P. Parvy, H. Ogier, R. Girot, P. Manigne, and J. Frezal. 1983. Diet-responsive proconvertin (factor VII) deficiency in homocystinuria. J. Pediatr. 102:730-734.

11. Brattstrom, L., B. Israelsson, L. Tengborn, and B. Hultberg. 1989. Homocysteine, factor VII and antithrombin III in subjects with different gene dosage for cystathionine- $\beta$-synthase. J. Inherited Metab. Dis. 12:475-482.

12. Uhlemann, E. R., J. H. Ten Pas, A. W. Lucky, J. D. Schulman, S. H. Mudd, and N. R. Shulman. 1976. Platelet survival and morphology in homocystinuria due to cystathionine synthase deficiency. N. Engl. J. Med. 295:12831286.

13. Hill-Zobel, R., R. E. Pyeritz, U. Scheffel, O. Malpica, S. Engin, E. E. Camargo, M. Abbott, T. R. Guilarte, J. Hill, P. A. McIntire, et al. 1982. Kinetics and distribution of 111-indium-labeled platelets in patients with homocystinuria. N. Engl. J. Med. 307:781-786.

14. Patrono, C., G. Davì, and G. Ciabattoni. 1992. Thromboxane biosynthesis and metabolism in relation to cardiovascular risk factors. Trends Cardiovasc. Med. 2:15-20.

15. Vesterqvist, O., and K. Green. 1984. Urinary excretion of 2,3-dinorthromboxane $\mathrm{B}_{2}$ in man under normal conditions, following drugs and during some pathological conditions. Prostaglandins. 27:627-644.

16. Di Minno, G., and M. Mancini. 1990. Measuring plasma fibrinogen to predict stroke and myocardial infarction. Arteriosclerosis. 10:1-7.

17. Salem, H. H. 1986. The natural anticoagulants. Clin. Haematol. 15:371391.

18. Lijnen, H. R., and D. Collen. 1989. Congenital and acquired deficiencies of components of the fibrinolytic system and their relation to bleeding or thrombosis. Fibrinolysis. 3:67-77.

19. Kaplan R, H. S. Aynedjian, D. Schlondorff, and N. Bank. 1990. Renal vasoconstriction caused by short-term cholesterol feeding is corrected by thromboxane antagonist or probucol. J. Clin. Invest. 86:1707-1714.

20. Mudd, S. H., and H. L. Levy. 1989. Disorders of transsulfuration. In The Metabolic Basis of Inherited Disease. C. R. Scriver, A. L. Beaudet, W. S. Sly, and D. Valle, editors. McGraw-Hill, New York. 693-734.

21. Spackman, D. H., W. H. Stein, and S. Moore. 1958. Automatic recording apparatus for use in the chromatography of amino acids. Anal. Chem. 30:11901206.

22. Fleisher, L. D., H. H. Tallan, N. G. Beratis, K. Hirshhorn, and G. E. Gaull. 1973. Cystathionine synthase deficiency: heterozygote detection using cultured skin fibroblasts. Biochem. Biophys. Res. Commun. 55:38-44.

23. Di Minno, G., F. Coraggio, A. M. Cerbone, A. M. Capitanio, C. Manzo, M. Spina, P. Scarpato, G. M. R. Dattoli, P. L. Mattioli, and M. Mancini. 1986. A myeloma paraprotein with specificity for platelet glycoprotein IIIa in a patient with a fatal bleeding disorder. J. Clin. Invest. 77:157-164.

24. Ciabattoni, G., J. Maclouf, F. Catella, G. A. FitzGerald, and C. Patrono. 1987. Radioimmunoassay of 11-dehydro- $\mathrm{TXB}_{2}$ in human plasma and urine. Biochim. Biophys. Acta. 918:293-297.

25. Ciabattoni, G., F. Pugliese, G. Davì, A. Pierucci, B. M. Simonetti, and C. Patrono. 1989. Fractional conversion of thromboxane $B_{2}$ to urinary 11-dehydrothromboxane $\mathrm{B}_{2}$ in man. Biochim. Biophys. Acta. 922:66-70. 
26. Patrono, C., G. Ciabattoni, G. Remuzzi, E. Gotti, S. Bombardieri, O. Di Munno, G. A. Tartarelli, B. M. Simonetti, and A. Pierucci. 1985. Functional significance of renal prostacyclin and thromboxane $A_{2}$ production in patients with systemic lupus erythematosus. J. Clin. Invest. 76:1011-1018.

27. Di Minno, G., A. M. Cerbone, F. Cirillo, A. Postiglione, M. Colucci, N. Semeraro, N. Scarpato, A. Gnasso, M. Margaglione, G. Gallotta, et al. 1990. Hemostatic variables in homozygous familial hypercholesterolemia. The effect of a regular cholesterol removal by LDL-apheresis. Arteriosclerosis. 10:1119-1126.

28. Roberts, L. J., II, B. J. Sweetman, and J. A. Oates. 1981. Metabolism of thromboxane $\mathbf{B}_{2}$ in man. Identification of twenty urinary metabolites. J. Biol. Chem. 256:8384-8393.

29. Burch, J. W., N. Stanford, and P. W. Majerus. 1978. Inhibition of platelet prostaglandin synthetase by aspirin. J. Clin. Invest. 61:314-319.

30. Patrignani, P., P. Filabozzi, and C. Patrono. 1982. Selective, cumulative inhibition of platelet thromboxane production by low-dose aspirin in healthy subjects. J. Clin. Invest. 69:1366-1372.

31. FitzGerald, G. A., J. A. Oates, J. Hawiger, R. L. Maas, L. Jakson Roberts, J. A. Lawson, and A. Brash. 1983. Endogenous biosynthesis of prostacyclin and thromboxane and platelet function during chronic administration of aspirin in man. J. Clin. Invest. 71:676-688.

32. Di Minno, G., M. J. Silver, A. M. Cerbone, and S. Murphy. 1986. Trial of repeated low-dose aspirin. Blood. 68:886-891.

33. Catella, F., and G. A. FitzGerald. 1987. Paired analysis of urinary thromboxane $\mathrm{B}_{2}$ metabolites in humans. Thromb. Res. 47:647-656.

34. Witzum, J. L., and D. Steinberg. 1991. Role of oxidized low density lipoprotein in atherogenesis. J. Clin. Invest. 88:1785-1792.

35. Clarke, R., L. Daly, K. Robinson, E. Naughten, S. Cahalane, B. Fowler, and I. Graham. 1991. Hyperhomocystinemia: an independent risk factor for vascular disease. N. Engl. J. Med. 324:1149-1155.

36. Davì, G., I. Catalano, M. Averna, A. Notarbartolo, A. Strano, G. Ciabat- toni, and C. Patrono. 1990. Thromboxane biosynthesis and platelet function in type-II diabets mellitus. N. Engl. J. Med. 322:1769-1774.

37. Davì, G., M. Averna, I. Catalano, C. Barbagallo, A. Ganci, A. Notarbartolo, G. Ciabattoni, and C. Patrono. 1992. Increased thromboxane biosynthesis in type Ila hypercholesterolemia. Circulation. 85:1792-1798.

38. Heinecke, J. W., H. Rosen, L. A. Suzuki, and A. Chait. 1987. The role of sulfur-containing amino acids in superoxide production and modifications of low density lipoprotein by arterial smooth muscle cells. J. Biol. Chem. 262:1009810103.

39. Parthasarathy, S. 1987. Oxidation of low density lipoprotein by thiol compounds leads to its recognition by the acetyl LDL receptor. Biochim. Biophys. Acta. 917:337-340.

40. Ardlie, N. J., M. L. Selley, and L. A. Simons. 1989. Platelet activation by oxidatively modified low density lipoproteins. Atherosclerosis. 76:117-124.

41. Graeber, J. E., J. H. Slott, R. E. Ulane, J. D. Shulman, and M. J. Stuart. 1982. Effect of homocysteine and homocystine on platelet and vascular arachidonic acid metabolism. Pediatr. Res. 16:490-493.

42. Parthasarathy, S., S. G. Young, J. L. Witzum, R. C. Pittman, and D. Steinberg. 1986. Probucol inhibits oxidative modification of low density lipoproteins. J. Clin. Invest. 77:641-644.

43. Akeson, A. L., C. W. Woods, L. B. Mosher, C. E. Thomas, and R. L. Jackson. 1991. Inhibition of IL-1 $\beta$ expression in THP-1 cells by probucol and tocopherol. Atherosclerosis. 86:261-270.

44. Ku, G., N. S. Doherty, L. F. Schmidt, R. L. Jackson, and R. J. Dinerstein. 1990. Ex vivo lipopolysaccharide-induced interleukin-1 secretion from murine peritoneal macrophages inhibited by probucol, a hypocholesterolemic agent with antioxidant properties. FASEB (Fed. Am. Soc. Exp. Biol.) J. 4:1645-1653.

45. Mao, S. J. T., M. T. Yates, R. A. Parker, E. M. Chi, and R. L. Jackson. 1991. Attenuation of atherosclerosis in a modified strain of hypercholesterolemic Watanabe rabbits with use of a probucol analogue (MDL 29,311) that does not lower serum cholesterol. Arteriosclerosis Thrombosis. 11:1266-1275. 